\title{
Research on Value Management of Astronautical Enterprises in the Context of Military and Civilian Integration
}

\author{
Wu Baolin ${ }^{1, a}$, Tian Yezhuang ${ }^{2, b}$ \\ ${ }^{1}$ School of Management, Harbin Institute of Technology, Harbin, 150001, China \\ ${ }^{1}$ School of Management, Harbin Institute of Technology, Harbin, 150001, China \\ aemail: muguatan@126.com, bemail: livfang@126.com
}

Keywords: military and civilian integration; astronautical enterprise; value creation; value management

\begin{abstract}
In the context of military and civilian integration, value maximization becomes an essential requirement for the self-development of astronautical enterprises. Therefore, the question of how to improve enterprise value becomes an important concern for astronautical enterprises. Based on profound research on theories relating to value creation and value management and useful experiences of well-known enterprises at home and abroad, and on the basis of the value chain theory, this paper closely combines the development characteristics of astronautical enterprises in the broader context of military and civilian integration, analyzes changes within the astronautical enterprise value chain, constructs the value management model of astronautical enterprises in the context of military and civilian integration.
\end{abstract}

\section{Foreword}

"Military and civilian integration" is the sensible approach which is being explored by our country as part of its programme of modernization and the development of national defense, as well as the strategic core of our national defense affairs, in this new era of development. It was proposed in the Report of $18^{\text {th }}$ CPC National Congress that we should: "build strong national defense and powerful armed forces that are commensurate with China's international standing, and meet the needs of its security and development interests" and, in order to realize this goal, we need to "be guided by China's core security needs, as well as integrating economic development and national defense construction". In the context of military and civilian integration, the mission of astronautical enterprises is no longer limited to defending national security interest. Instead, it is expanded to the main battlefield of national economic development and the creation of value for society and the enterprise itself. Since 2007, China, for the first time, has introduced the Economic Value Added (EVA) into the evaluation system in the document of Interim Procedures for Business Performance Evaluation of Responsible Persons of Central Enterprises carried out by the State-owned Assets Supervision and Administration Commission (SASAC) to encourage central enterprises to use EVA as their business performance evaluation index, which means that, since that point, the central enterprises have entered into a new stage of value management with enterprise value maximization and sustainable development as the core values. Therefore, research into value management of astronautical enterprises is of key theoretical and practical importance.

\section{Value management}

As the hottest management concept in recent years, value management is a brand new enterprise management model which has been explored by well-known international enterprises to meet the demands of economic globalization development. It breaks through the traditional management model with the value of the enterprise as the core of enterprise management, in order to realize the goal of enterprise value maximization. The emphasis is placed on the integration of enterprise market value and internal economic value[1].

Value chain theory is one of the most widely researched and applied value management theories, 
and is an important tool for enterprise value management. The value chain theory was first described and popularized by Michael Porter, professor of Harvard Business School. Mr. Porter indicated in his book Competitive Advantage that for enterprises, the production management processes were mutually dependent and interrelated, and these links could create value for enterprises, and final profit of enterprises exactly comes from the specific value activities of these different chains within the enterprises. This is the so-called value chain. The value chain is a form which exists objectively, and reflects the value creation process and value added economic process. The value chain is an organic integrity which is composed of interdependent value activities of the enterprise and represents the life-cycle management of products and services relating to the enterprises concerned. According to value chain theory, the value activities of an enterprise can be divided into basic activities and auxiliary activities[2],[3].

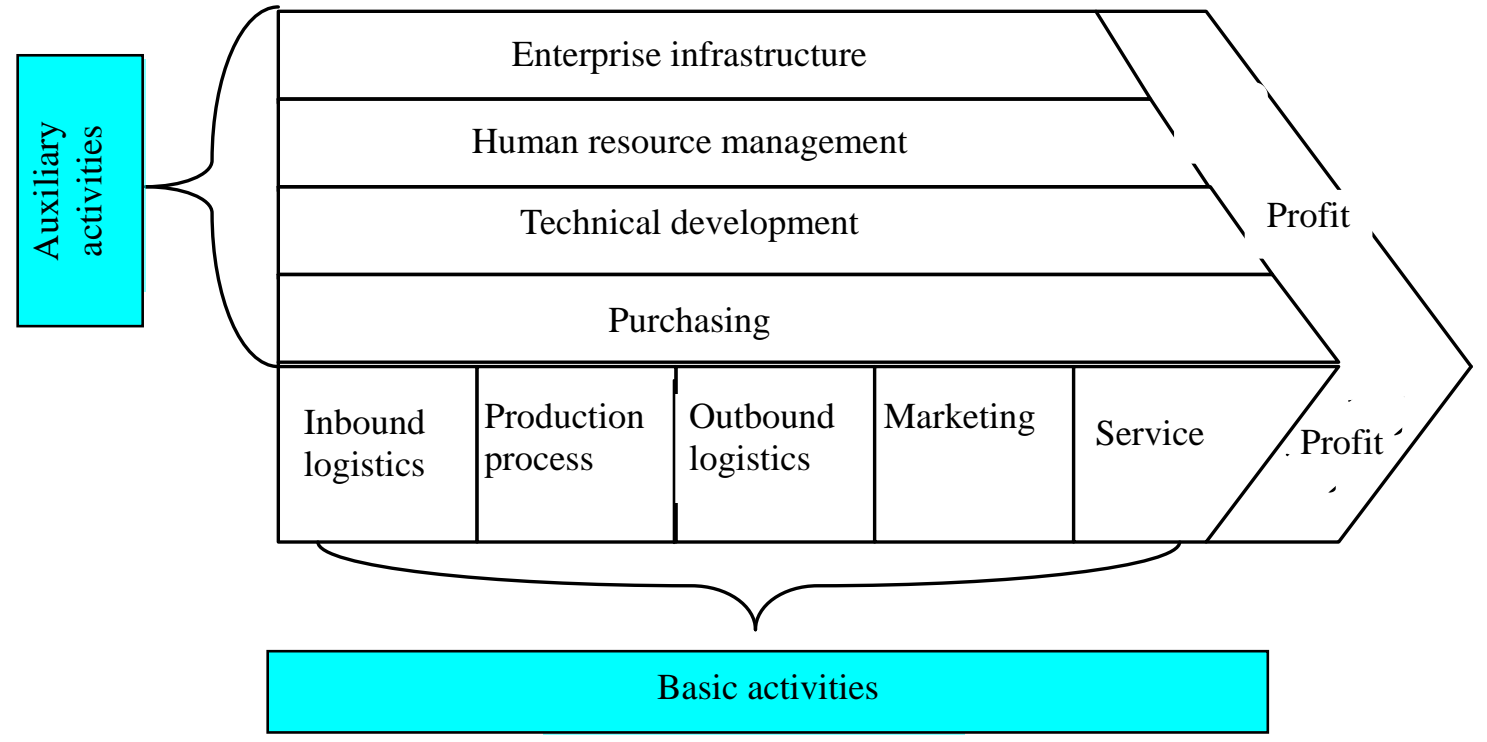

Fig.1. Michael Porter’s Value Chain Theory

\section{Analysis of the astronautical enterprise value chain}

\subsection{Management elements of task-based astronautical enterprises}

The phrase "task-based astronautical enterprise" refers to astronautical enterprises which focus on military products. The management work is carried out around aerospace model tasks, and mainly refers to the management of the model project. Value is evaluated through various value measurements and aims to assess value brought by the model project to the field of defense-related science and technology in a comprehensive way so as to facilitate astronautical enterprises to fully make use of limited resources and complete the model project in an efficient manner. Analysis of task-based astronautical enterprise management elements is performed on three levels, namely: the organizational element, flow element, and operation element, as shown in Figure 2. 


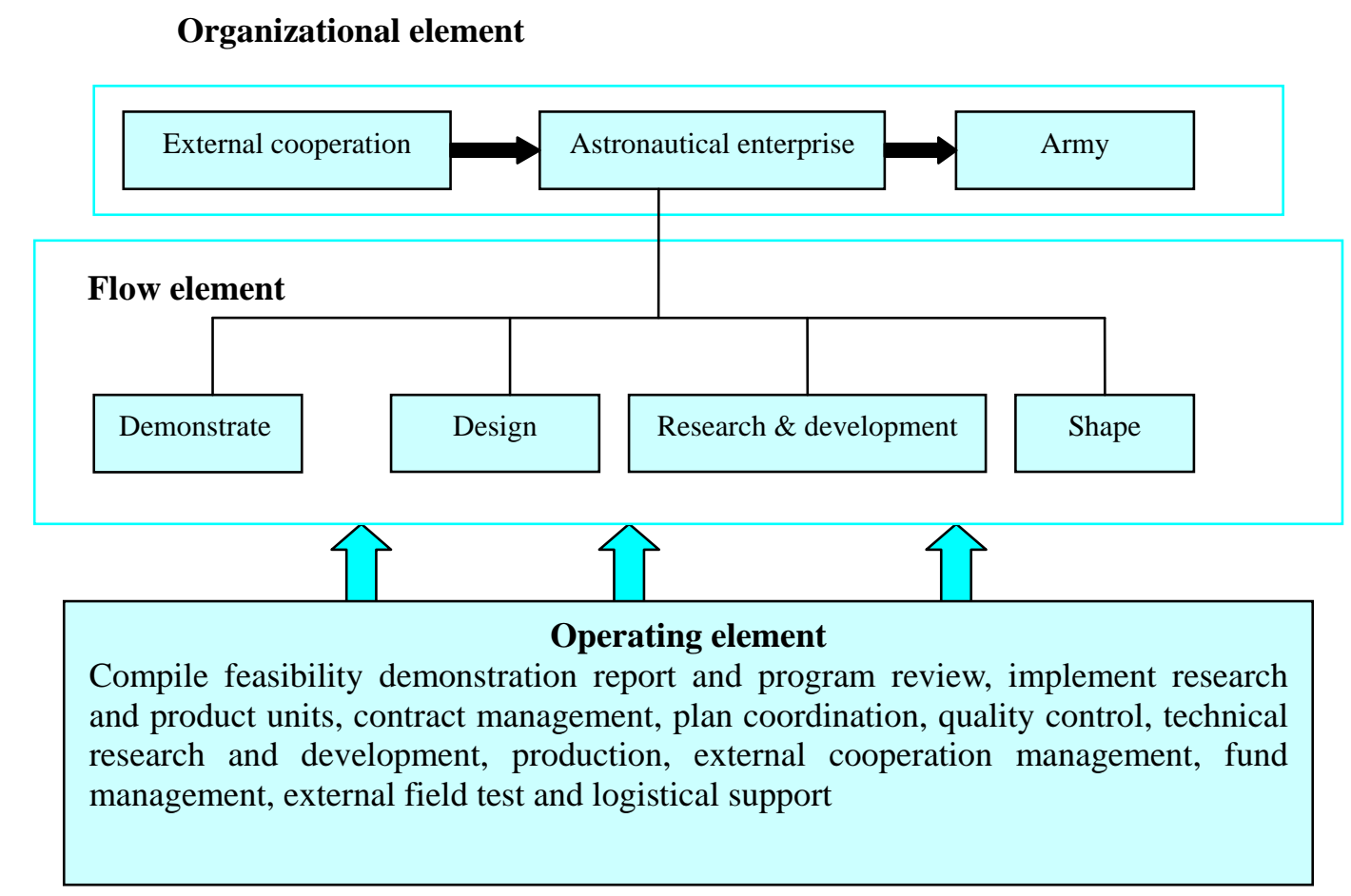

Fig.2. Analysis of Value Management Elements of Task-Based Astronautical Enterprises

\subsubsection{Organizational element}

The organizational element of task-based astronautical enterprises mainly comprises the external cooperation unit, internal departments of astronautical departments (including the planning department, quality department, research and development department, production department, finance department and operations department) and the army.

\subsubsection{Flow element}

The flow element of the task-based astronautical enterprise mainly comprises demonstration, program design, engineering research and development, design shaping, technique and production shaping. The flow element of the task-based astronautical enterprise basically covers each stage of the model research process and each stage has a direct relationship with the model product.

\subsubsection{Operating element}

The operating element of the task-based astronautical enterprises mainly comprises the compilation of a feasibility demonstration report, program review and determination of research unit, contract management, planning coordination, quality control, technical research and development, production, external cooperation management, fund management, external field testing and logistical support, etc.

\subsection{Management elements of civilian products of astronautical enterprises in the context of military and civilian integration}

The military and civilian integrated astronautical enterprises break with the traditional closed and task-based scientific research production management model. Management focus is no longer on the model project value management alone, instead, it depends more on the development of civil industry, and strives to develop an integrated military and civilian industry, alongside major projects, and develops potential of astronautical enterprises, in order to combine the construction of national defense military hardware with organic economic development, and to form a new economic growth point, as well as comprehensively improving the value of the astronautical enterprises.

In the context of military and civilian integration, the astronautical enterprise, as the market competition subject, will be involved in civilian product market competition to a great extent, and will become a link to the whole industry or section. The organizational element of it includes: the supplier and customer, the flow element includes demand analysis, concept design, technical development, production (that is: manufacturing, marketing, after-sales service and related 
commodity life-span flow) and the operating element is completely combined with the market, and focuses on cost control.

\subsection{Value chain of astronautical enterprise in the context of military and civilian integration}

Based on the above-mentioned analysis, the internal chain value of military and civilian integration astronautic enterprise is thus constructed. The chain value structure of it includes the military product longitudinal value chain, the civilian product longitudinal value chain, and the horizontal value chain linking all elements[4], as shown in Figure 3.

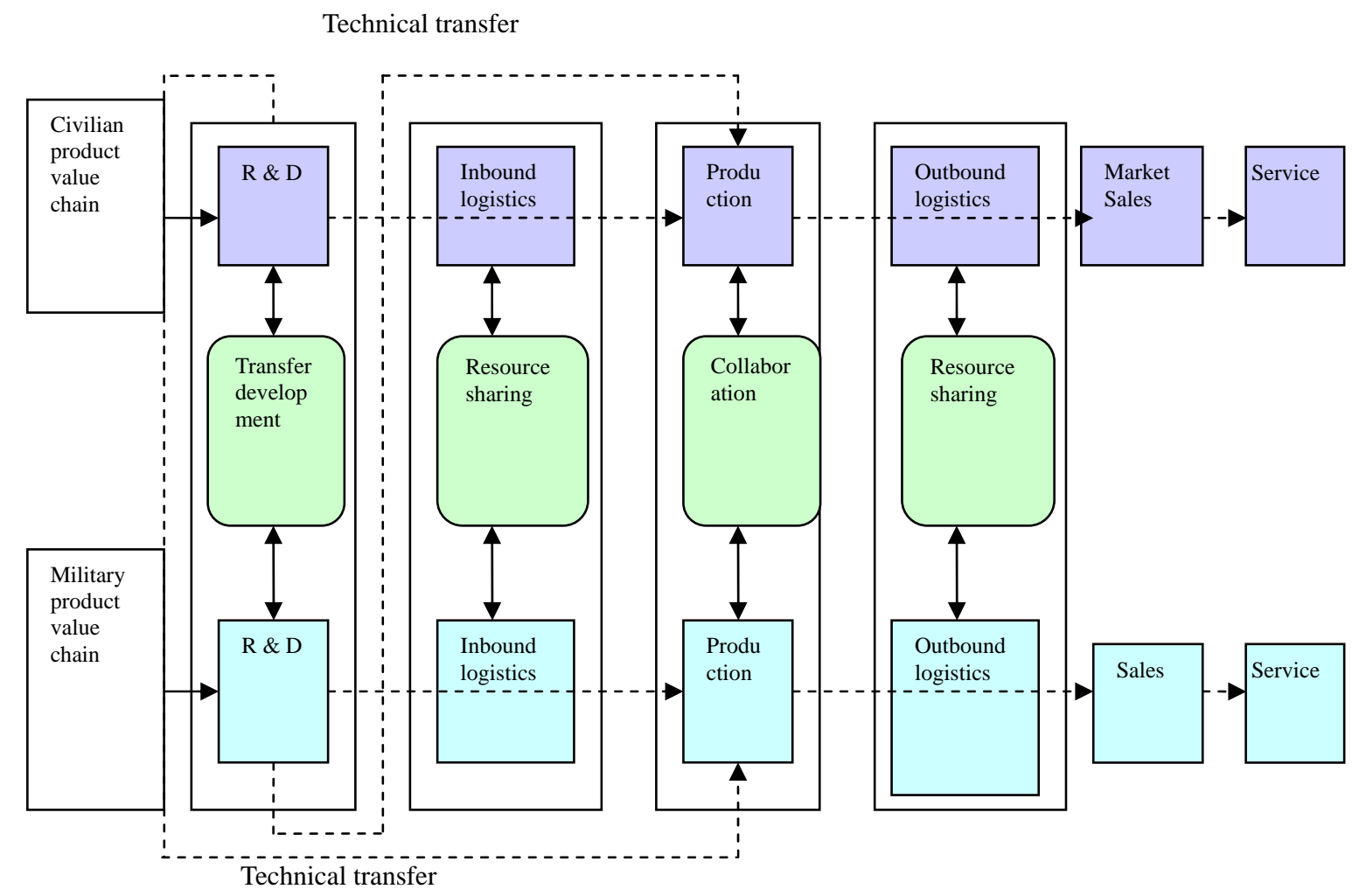

Fig.3. Value Chain of Astronautical Enterprises in the Context of Military and Civilian Integration

The longitudinal value chain network is a kind of link chain within the internal military product or civilian product departments of an astronautical enterprise, which is composed of all value formation and transfer links ranging from the input of raw material to the final user product formation period. The horizontal value chain network is the chain of cooperative relationship in the value formation link between product research and production and technical transfer in internal military product and civilian product departments of astronautical enterprises, that is to say, the chain of interactions between similar links in the mutual-parallel longitudinal value chain. Military and civilian product departments of astronautical enterprises (in the context of military and civilian integration) form a relationship and structure involving value generation, distribution, transfer and usage through coupling the interaction of the research and development capacity, technical transfer and resource sharing, and therefore forms the basic value chain network of military and civilian integration[5].

From this figure we can see, as a complex system, the value chain network of military and civilian integration astronautic enterprise involves, besides market sales, service and related value chain links with relatively significant differences, a military and civilian integrity value chain network formed by the collaboration of military products and civilian products in a research and development capacity, logistics and production links, which makes the astronautical enterprises fully take advantage of military technology so as to develop civilian products and effectively utilize production resources to reduce cost of resources, and improve upon enterprise performance. 


\section{Value management model of astronautic enterprise in the context of military and civilian integration}

Based on the analysis of the value chain, and the adjustment of the astronautical enterprises in the context of military and civilian integration, and making reference to the value management experience of enterprises both at home and abroad, this research tries to construct a value management model for astronautical enterprises in the context of military and civilian integration through the use of strategic planning, strategic implementation, incentive mechanism and governance and optimization as the basis for the research[6].

\subsection{Strategic planning as oriented by value creation}

Strategic planning is an important part of value management. The establishment process for strategy for the military and civilian integration of astronautical enterprises must be carried out around value creation and adequate attention must be paid to opportunities for value creation, whilst simultaneously ensuring that all business units and management personnel of astronautic enterprises know details the influence of management activities on astronautic enterprise value, in order to promote collaboration and cooperation of military and civilian value chains as well as reinforcing cost management.

\subsubsection{Pre-phase analysis}

Before making a strategic plan, we must analyze the problems involved. The analysis of problems involved in military and civilian integration astronautical enterprises can be done through military and civilian value chain analysis, enterprise value evaluation, external development environment analysis and the analysis of internal problems within enterprises, with the aim of clarifying the nature of any problems, opportunities and challenges faced by the strategic establishment.

\subsubsection{Strategic planning}

Taking value as the standard of measurement to evaluate all programs proposed, and identify the program option.

\subsubsection{Comprehensive budget}

Firstly, divide the optional program into different obligatory goals and implement and issue to the budget performer. Secondly, control the implementation conditions of the budget, compile a report of budget implementation results, and analyze the differences between actual implementation and expectancy. Finally, check and evaluate the budget implementation result of responsible internal departments or responsible centers of the enterprise involved.

\subsection{Strategic implementation, with value promotion as the objective}

During the strategic implementation stage, connect the work plans of all departments with an effective strategic plan, and implement tasks step by step, in order to carry out value creation activities. In most cases, it includes the following three links:

\subsubsection{Organizational structure adjustment and reconstruction}

Analyze the value chain of military and civilian integration astronautical enterprises, clarify measures to make up value gaps, make improvements which target original organizational structure problems, and strengthen the organizational structure construction, strengthening weak links such as marketing and after-sales service. Meanwhile, break the departmental structure divisions in accordance with the model project, develop a professional structure allocation which is beneficial to value management, and connect the departmental plan with the strategic plan in an effective manner. The astronautical enterprise can merge and restruct external resources to meet demands presented by the competition.

\subsubsection{Business adjustment}

Reallocate the functions of the astronautical enterprises on the basis of organizational restructuring, transform the function-based astronautical enterprise into a value chain flow-based one, break the functional separation of military and civilian departments, and perform collaboration between military and civilian industries, according to the demands of business flow. Focus should be on the system optimization of business flow and the realization of the close combination of business flow and personnel. 


\subsubsection{Optimization of resource allocation}

Realize the integration of resources to the maximum level, reallocate human resources, financial resources and material resources according to business demands, and transform security-based resource allocation to an effect-based one. Strengthen the transfer of military technology and the sharing of military and civilian resources to ensure maximum usage of resources and reduce cost to the maximum degree, therefore creating value.

\subsection{Performance evaluation, with value management as the central concept}

Astronautical enterprises in the context of military and civilian integration must make performance evaluation and assessment for the astronautical enterprises themselves, and carry out active and positive management of the value chain aiming at the results. The stability and efficiency of the value chain must be ensured, and the potential ability of astronautical enterprise value must be fully demonstrated.

\subsubsection{Evaluation subject}

The evaluation subject of the performance of military and civilian integration for astronautical enterprise can potentially include diverse interest related parties such as: the government, administrator, supplier and customer.

\subsubsection{Evaluation object}

The performance evaluation object of the astronautical enterprises (based on value) can be divided into three parts, which namely: enterprise integrity, the department, and the individual.

\subsubsection{Evaluation index system}

Gradually reform the evaluation system and establish the performance evaluation index system through the use of Economic Value Added (EVA) system as the core element.

\subsection{An Incentive system, with value creation as the core element.}

A military and civilian integration astronautical enterprise must strengthen the development of its incentive system, pay attention to any increase of its evaluation object value, and handle the following relationships: The first element is the relationship between the economic and non-economic incentives, through training and developing various types of non-economic incentives such as the opportunity incentive, target incentive, honor incentive and negative incentive at the same time as the economic incentive. The second is the relationship between group performance and individual performance, combining group performance with individual performance, when establishing the incentive plan and establishing group remuneration on the basis of group performance and meanwhile identifying individual shares in group performance, according to individual performance criteria. The third element is the relationship between accounting-based performance and market-based performance, the general accounting index is suitable for management personnel and common personnel, but it is inappropriate for market personnel, and therefore we must establish a market-based index in order to carry out checking and incentive.

\section{Suggestions}

Based on the above-mentioned analysis, this paper considers that the astronautical enterprise must carry out value management based on the following criteria: Firstly, establish the value management mode of thinking, with value maximization as the strategic target, so as to lay a good ideological basis for the value creation and value management activities of the astronautical enterprises. Secondly, vigorously implement an innovation-driven strategy to improve the value creation ability of the astronautical enterprise involved. Thirdly, integrate the value chain to the fullest degree, and improve upon core competitiveness of the core business and implement high value-added business. Fourthly, strengthen the intangible assets management elements such as the brand and patent and improve upon enterprise profitability analysis. Fifthly, strengthen the management of weak links within value management such as purchasing and marketing, and strengthen the market operational capacity of the astronautical enterprises.

A new era and new mission has dawned for astronautical enterprises, in which the full importance of value creation is realised, in order to accelerate the transformation of development mode and lay a solid foundation for the realization of the historical mission of building a prosperous 
country and a strong army.

\section{References}

[1] Luo Fei. Management Research Based on Value [D]. Changchun : Dongbei University of Finance and Economics, 2007:1-8.

[2] Shanghai National Accounting Institute. Value Management [M]. Beijing: Economic Science Press. 2011:73-77

[3] Feng Hailong. Research on the Value Chain Strategic Management Model [J]. Economic Management. New Management. 2002 (10): 40-45

[4] Zhang Yingnan. Research on the Motivation of Military and Civilian Integrity of Military Industrial Enterprise and Formation Mechanism [D]. Harbin: Harbin Institute of Technology. 2010:40-65.

[5] Zhang Yingnan, Jiang Zhenhuan. Research on the Cooperative Relationship and Cooperative Effects in the Military and Civilian Value Chain Network in Military Industrial Enterprise [J]. Technical economy 2009 (9): 109-113.

[6] He Ying. Construction of Enterprise Value Management Model [J]. Economic management New management. 2005(12): 26-31. 